\title{
DEMOCRACIA, O SOBERANO IMANENTE E O FIM DA EXCEÇÃO: UMA CRÍTICA AO DECISIONISMO DE CARL SCHMITT
}

\section{DEMOCRACY, THE IMMANENT SOVEREIGN AND THE END OF EXCEPTION: A CRITIQUE OF CARL SCHMITT'S DECISIONISM}

\author{
Cássio Corrêa Benjamin ${ }^{1}$
}

\section{RESUMO}

O decisionismo é a estrutura do pensamento político e jurídico de Schmitt. Por isso, a famosa figura da exceção. Por isso, também, a figura central do soberano teísta. Nosso objetivo nesse artigo é a análise dos pressupostos do decisionismo de Schmitt, mostrando como tais pressupostos são incompatíveis com a imanência e, portanto, com a democracia. Apresentaremos, então, alguns traços centrais de uma noção de democracia baseada na imanência, como o fim da exceção e o soberano imanente. Metodologicamente, faremos uma leitura dos escritos de Schmitt nos quais a noção de decisionismo é elaborada, além de comentadores destacados que tratam da questão.

Palavras-chave: Decisionismo, exceção, soberano, democracia, imanência

\begin{abstract}
Decisionism is the structure of Schmitt's political and legal thought. Hence the famous figure of the exception. Hence, too, the central figure of the theistic sovereign. Our objective in this article is to analyze the assumptions of Schmitt's decisionism, showing how such assumptions are incompatible with immanence and, therefore, with democracy. We will then present some central features of a notion of democracy based on immanence, such as the end of the exception and the immanent sovereign. Methodologically, we will read Schmitt's writings in which the notion of decisionism is elaborated, in addition to prominent commentators who deal with the issue.
\end{abstract}

Keywords: Decisionism, exception, sovereign, democracy, immanence

\section{INTRODUÇÃO}

O decisionismo deve ser levado a sério para a correta compreensão de Schmitt e das consequências do seu pensamento, principalmente no que concerne à questão que nos interessa

\footnotetext{
${ }^{1}$ Graduação e mestrado em Filosofia pela Universidade Federal de Minas Gerais (UFMG). Doutor em Ciência Política pela Universidade Federal de Minas Gerais (UFMG). Professor Associado da Universidade Federal de São João del-Rei (UFSJ). Leciona no curso de Filosofia do DFIME (Departamento de Filosofia e Métodos). Afiliação: Universidade Federal de São João del Rei. Lattes: http://lattes.cnpq.br/2552981991319482. ORCID: https://orcid.org/0000-0003-4002-7980. E-mail: ccbenj@ufsj.edu.br
} 
aqui, a saber, a democracia. Não há democracia em Schmitt porque o seu pensamento estrutura-se em torno do decisionismo: democracia e decisionismo são incompatíveis ${ }^{2}$. O decisionismo como estrutura central das reflexões de Schmitt impede qualquer aproximação de fato do pensamento democrático porque tal decisionismo é uma figura estranha à imanência ${ }^{3}$. Vamos, então, à análise do decisionismo para apresentar suas características e traços fundamentais. Só assim ficará clara a crítica que estamos fazendo a Schmitt.

A primeira questão que deve ser colocada é sobre o porquê do decisionismo. Qual é a questão que o decisionismo pretende solucionar, por que ele aparece na obra de Schmitt? Muitas discussões ocorrem em torno do decisionismo. São muitos os aspectos que ele suscita e sugere. Entretanto, gostaríamos de ressaltar uma característica específica, uma questão própria. De forma bem abstrata, gostaríamos de salientar que o decisionismo se refere a um juízo, a uma justificação, a uma razão. A repetida afirmação de Schmitt sobre o caráter existencial de uma decisão e sua contraposição ao normativismo não devem levar à desatenção sobre o problema eminente da busca de um fundamento. É isso o que estamos chamando aqui de assimetria. O decisionismo é uma forma muito específica de traçar essa assimetria, de justificar uma distinção. O que justifica que uma regra ou norma seja caracterizada como assimetricamente preferível em relação a outras? Por que escolher uma norma ou regra em detrimento de outras? Em suma, como traçar essa assimetria? A resposta para essa pergunta exige que se aponte uma distinção e que essa distinção seja justificada de algum modo. O decisionismo é uma resposta para essa pergunta. Embora não seja aqui o lugar para uma discussão mais ampla sobre o tema, apenas lembraríamos da permanência e atualidade dos problemas que o decisionismo coloca ${ }^{4}$.

Antes de passarmos a uma análise mais detalhada, gostaríamos de ressaltar que Schmitt, muito corretamente, situa o decisionismo em um âmbito muito mais amplo do que simplesmente uma questão jurídica. O decisionismo, de fato, é também uma questão jurídica. O tratamento do

\footnotetext{
${ }^{2}$ Nossa hipótese é de que há uma continuidade entre Teologia Política (1996c), Catolicismo Romano e Forma Política (1984) e a Teoria da Constituição (2003). De forma contínua, embora levemente distinta, o tema do decisionismo permanece.

${ }^{3}$ É essa tensão insolúvel entre a estrutura da transcendência do decisionismo e a imanência da democracia, como veremos na sequência do texto, que explica o lugar ambíguo da representação em Schmitt: "representar significa presentificar e tornar visível um ser não visível através de um ser presente publicamente" (SCHMITT, 2003, p.209). Essa discussão reaparece em vários textos centrais sobre a representação como, por exemplo, aquele de Hanna Pitkin: The Concept of Representation. Há no livro um breve comentário sobre Schmitt. O que chama a atenção é que a noção mais abstrata de representação pensada por Pitkin é exatamente aquela noção da transcendência de Schmitt: representar é tornar presente um ausente (PITKIN, 1967, p.9). Outra referência importante é o livro de Hofmann: Repräsentation (2003). Schmitt é discutido em várias passagens. Por fim, embora não trate diretamente de Schmitt, mas da tensão entre transcendência e imanência, temos o livro de Voegelin, The New Science of Politics (1952). Escapa aos nossos propósitos um comentário sobre as aproximações e distâncias do pensamento de Schmitt. Sobre a relação Voegelin - Schmitt, ver GALLI (1996, p.274).

${ }^{4}$ Em um texto sobre o problema de legitimação no capitalismo tardio, Habermas, ao fazer uma crítica do conceito de legitimação de Weber, realiza uma aproximação entre o decisionismo schmittiano e a concepção do direito de Luhmann (HABERMAS, 1975, p.98).
} 
decisionismo como uma questão do campo próprio do direito recebe, portanto, um papel destacado por parte de Schmitt. Obviamente, isso não poderia ser diferente em se tratando de um jurista, mas o decisionismo vai muito além da discussão jurídica e Schmitt tem plena consciência disso. Em sua Teologia Política (1996c), há várias passagens referentes à teologia, à política, à ciência. Um espaço privilegiado para uma boa percepção da amplitude do tema do decisionismo é, particularmente, o capítulo terceiro cujo título é exatamente Teologia Política. Ali, como evidencia o título, tem-se uma ampla discussão do lugar do decisionismo na teologia, sua aproximação ao teísmo e contraposição ao deísmo. Além disso, é desenhada uma oposição entre decisionismo e as ciências naturais. É, portanto, bastante extenso o campo de questões do decisionismo. Faremos, então, uma apresentação da estrutura do decisionismo para apresentar algumas de suas características. São tais características que nos permitirão o entendimento da questão da democracia.

\section{DECISIONISMO}

Comecemos com o livro Teologia Política (1996c). Schmitt abre seu livro com a notória definição de soberano: "soberano é aquele que decide sobre o estado de exceção [Ausnahmezustand]" (SCHMITT, 1996c, p.13). A relação entre decisão e exceção é necessária e é apenas ela que nos faz compreender o significado exato do decisionismo. É isso o que faz Schmitt afirmar que a decisão sobre a exceção é decisão em sentido eminente. O oposto da exceção é uma norma geral. A intenção de Schmitt ao levar a ideia de decisão e exceção para o âmbito jurídico fica clara quando ele afirma que a norma geral é a expressão de uma sentença jurídica normalmente válida. Essa é a composição típica do Estado de direito que ele pretende criticar. O problema de uma norma geral é que ela nunca pode abranger uma exceção. Logicamente, portanto, ela não pode fundamentar uma decisão. E, como para Schmitt, há exceção, então, a norma geral e, consequentemente, o Estado de direito não estão à altura da questão central do direito. É esse o mote que será repetido por Schmitt não apenas ao longo de todo o livro, como também em outras obras.

Schmitt oferece uma descrição mais específica que possibilita uma definição ainda mais precisa do decisionismo e de sua relação com a exceção. É uma descrição por negação: “o caso de exceção [Ausnahmefall], aquele caso não circunscrito na ordem jurídica válida" (SCHMITT, 1996c, p.13). Esse é o ponto fundamental para a compreensão a exceção. Novamente, a exceção situa-se fora da norma geral, a exceção não pode ser circunscrita em uma ordem jurídica do Estado de direito. Surge, então, a figura do soberano: "este caso [da exceção] torna atual a pergunta sobre o sujeito da soberania, ou seja, a pergunta sobre a soberania em geral" (SCHMITT, 1996c, p.14). Começa-se a compreender então como Schmitt pensa o lugar do soberano como o espaço da 
exceção e como ele é o lugar da decisão. Se não existisse exceção quanto às normas gerais do âmbito jurídico, não haveria a necessidade do soberano. A exceção é uma figura tão radical que em relação a ela "em um sentido legal estatal, não se apresenta nenhuma competência. A Constituição pode no máximo indicar quem deve agir em um tal caso" (SCHMITT, 1996c, p.14). É a partir dessa constatação que Schmitt afirma que o soberano "situa-se fora da ordem legal normalmente válida e, no entanto, pertence a ela, pois ele é competente para a decisão de suspender a Constituição in toto" (SCHMITT, 1996c, p.14). Contra a visão predominante do constitucionalismo, como entendido pela tradição liberal, a Constituição implica a existência de alguém com a capacidade de suspendê-la, já que, para Schmitt, Constituição é decisão ${ }^{5}$. É nesse sentido que ele diz com muita propriedade que "todas as tendências do desenvolvimento estatal jurídico moderno vão no sentido de eliminar o soberano" (SCHMITT, 1996c, p.14). Se uma visão das normas jurídicas como normas gerais predomina, então, não haveria a necessidade do soberano. Fundamentalmente, não haveria a necessidade da decisão. Como Schmitt afirma, se o caso extremo de exceção pode ser eliminado do mundo, isso não é uma questão jurídica, mas depende de convicções filosófico históricas e metafísicas.

Schmitt deriva com rigor as consequências da figura da exceção e do decisionismo. Comentando o estabelecimento de competências pelas normas jurídicas, Schmitt afirma que obviamente se houver competências claras para o caso de exceção, então a questão da soberania será afastada, mas não eliminada. A exceção exige nada menos do que "a suspensão de toda ordem existente" (SCHMITT, 1996c, p.18). A conclusão é muito clara: na exceção, o Estado permanece e o direito recua. Esse lugar intrigante da exceção é o lugar onde, por não ser anarquia e caos, há uma ordem, mas não uma ordem legal. A existência do Estado guarda uma superioridade sobre a validade da norma jurídica. A decisão é descrita de forma inequívoca: "a decisão se liberta de todo vínculo normativo e se torna, em um sentido próprio, absoluta" (SCHMITT, 1996c, p.18). Nada mais, nada menos do que isso. Deve ser citada aqui a outra passagem, tão explícita quanto essa, que mostra a radicalidade do que Schmitt entende por decisão: "considerado a partir do conteúdo da norma tida como base, aquele momento da decisão é algo novo e estranho. A decisão, normativamente considerada, nasce de um nada" (SCHMITT, 1996c, p.37). Aqui está a anteposição entre decisão e norma. Só desse modo se pode compreender porque é necessário que a decisão surja

\footnotetext{
${ }^{5}$ Deve-se considerar o sentido exato que tem a Constituição nos escritos de Schmitt. Constituição é decisão e não um conjunto de normas: "a Constituição em sentido positivo contém somente a determinação consciente de uma específica forma da totalidade para a qual decide uma unidade política" (SCHMITT, 2003, p.21). É essa compreensão que jogaria alguma luz sobre que estamos querendo chamar a atenção aqui, a saber, a permanência do decisionismo mesmo na Teoria da Constituição.
} 
de um nada normativo e, portanto, segundo qualquer norma, seja arbitrária ${ }^{6}$. Do ponto de vista normativo, portanto, o decisionismo é arbitrariedade. Esse é o ponto crucial do decisionismo ${ }^{7}$.

$\mathrm{Na}$ última parte do primeiro capítulo, em um processo de crescente abstração, Schmitt declara mais uma vez o seu fascínio pela figura da exceção. O racionalismo nega a exceção e afirma que só o objeto normal pode ter interesse científico, pois "a exceção perturba a unidade e ordem do esquema racional" (SCHMITT, 1996c, p.20). O que Schmitt denomina "uma filosofia da vida concreta" não deve recuar diante da exceção e do caso extremo, mas deve se interessar por eles de forma intensa, porque, para ela, "a exceção pode ser mais importante do que a regra" (SCHMITT, 1996c, p.21). Não só mais importante, Schmitt afirma também que "a exceção é mais interessante que o caso normal" (SCHMITT, 1996c, p.21). Isso ocorre porque "o normal não prova nada, a exceção prova tudo; ela não apenas comprova a regra, a regra vive em geral somente da exceção" (SCHMITT, 1996c, p.21). Em uma progressão de imagens grandiosas, Schmitt assevera que "na exceção, a força da vida efetiva rompe a crosta de uma mecânica rígida que se repete" (SCHMITT, 1996c, p.21). Kierkegaard é o teólogo protestante citado ${ }^{8}$. A parte mais importante da extensa citação é aquela que enuncia: "a exceção esclarece o geral e se esclarece a si mesma (...) a exceção pensa o geral com paixão enérgica" (SCHMITT, 1996c, p.21). Essa visão da exceção não desaparecerá do pensamento de Schmitt. Ela é a base da sua estrutura permanente do decisionismo.

No terceiro capítulo de sua Teologia Política, Schmitt apresenta a sua sociologia dos conceitos. Com tal sociologia, ele pode estabelecer analogias e semelhanças entre âmbitos distintos. No caso aqui em pauta, trata-se da relação entre teologia e jurisprudência, fundamentalmente no que diz respeito à noção de soberania. A partir da análise do conjunto de conceitos jurídicos, chegase à "estrutura última, radical e sistemática" (SCHMITT, 1996c, p.50) que deve ser comparada com "o emprego conceitual da estrutura social de uma determinada época" (SCHMITT, 1996c, p.50). Devem ser demonstradas as duas identidades espirituais, mas substanciais. Não entraremos na discussão sobre esse procedimento, sua correção ou validade para uma abordagem dos conceitos jurídicos e teológicos. O que nos interessa aqui é a discussão realizada em um âmbito mais abstrato do que aquela feita anteriormente. Agora não se trata apenas de um problema jurídico, mas como

\footnotetext{
${ }^{6}$ Schmitt oferece uma interpretação subjetivista e personalista para o decisionismo, em um polêmico texto escrito posteriormente à Teologia Política: "o normativista reivindica para si a justiça objetiva, impessoal, contra o arbítrio [Willkür] pessoal do decisionista" (SCHMITT, 2006, p.12). Essa interpretação extrema elimina a tensão, sempre presente na Teologia Política, entre a objetividade do caráter fundador do ato do soberano e a subjetividade do sujeito que decide. Strauss se refere a esse escrito como um "panfleto" (STRAUSS, 1995b, p.130).

${ }^{7}$ Se o decisionismo é arbitrário, do ponto de vista normativo, abre-se a questão de sua justificação. Portanto, não é em uma norma que poderemos encontrar a sua razão. Como veremos em detalhe, a interpretação majoritária, mesmo com algumas divergências, é a ideia de que a justificação da decisão soberana é sua capacidade de instaurar a ordem ou, dito de outra forma, o velho problema da realização do direito (Rechtsverwirklichung). Esse é o caso tanto de Galli (1996, p.333-347) quanto de Hofmann (2002, p.49-64).

${ }^{8}$ Para um comentário da referência a Sören Kierkegaard feita por Schmitt e a alteração do sentido da citação, ver HOFFMANN (2002, p.59).
} 
uma "sociologia dos conceitos" pretende mostrar, a questão envolve também a teologia. O que queremos destacar é o lugar bem mais amplo e fundamental no qual Schmitt quer estabelecer o seu decisionismo. Ele vai muito além de um mero problema do direito. Já havíamos ressaltado isso anteriormente, mas nesse capítulo esse aspecto fica bem nítido. Dito de outro modo, o decisionismo estabelece raízes bem profundas no pensamento de Schmitt.

O primeiro parágrafo desse capítulo é esclarecedor e lança as ideias principais que serão discutidas na sequência. Schmitt começa afirmando que "todos os conceitos relevantes da teoria moderna do Estado são conceitos teológicos secularizados" (SCHMITT, 1996c, p.43). Schmitt precisa dessa hipótese para que a sua sociologia dos conceitos tenha sentido. Não se trataria apenas de uma transmissão ou de um transporte de um conjunto de conceitos de um certo campo para o outro, no caso, da teologia para a teoria do Estado, quando o Deus todo poderoso se tornou o legislador onipotente. O que Schmitt busca é a "estrutura sistemática". Essa é sua tese forte. A exceção, então, tem um papel destacado aqui e apresenta analogias com a teologia: "o estado de exceção tem para a jurisprudência um significado análogo ao do milagre para a teologia" (SCHMITT, 1996c, p.43). Somente quando se tem consciência dessas semelhanças é possível compreender de modo consistente o desenvolvimento das ideias filosófico estatais dos últimos séculos.

Schmitt começa a diferenciar as noções básicas que constituem o conceito de Estado de direito daquelas utilizadas por ele para descrever o decisionismo, como a exceção. No plano teológico, o Estado de direito moderno é aproximado do deísmo e, por sua vez, o decisionismo se relaciona ao teísmo. Segundo Schmitt, portanto, a ideia de Estado de direito moderno é impregnada pelo deísmo, ou seja, "por uma teologia e metafísica que expulsa o milagre do mundo" (SCHMITT, 1996c, p.44). O deísmo nega a ruptura das leis naturais pela exceção através da intervenção imediata, assim como o soberano intervém de modo imediato na ordem jurídica vigente. Enquanto o racionalismo do Iluminismo rejeitava o caso de exceção em todas as suas formas, a convicção teísta dos escritores conservadores da contra-revolução (Donoso Cortes, de Maistre e de Bonald) fez com que eles tentassem fundar, com analogias, a soberania pessoal do monarca em uma teologia teísta. Estão aqui presentes as distinções e analogias principais com as quais Schmitt irá estabelecer a sua discussão. O deísmo é assemelhado ao Estado de direito e suas leis necessárias. Não há lugar para exceção, o que significa dizer que não há milagres. A exceção é aproximada da noção do milagre, o que mostra as analogias com o teísmo. A exceção exige o soberano, pois é ele quem suspende as leis vigentes. Como no teísmo, Deus pode suspender as leis naturais no instante do milagre. É a partir dessa sociologia dos conceitos que Schmitt irá dirigir a sua crítica polêmica contra o positivismo, contra Kelsen, contra o Estado de direito liberal, contra o racionalismo e outros adversários. 
Schmitt aponta várias semelhanças entre temas teológicos e as discussões que ocorrem em torno do Estado e do direito. Na literatura da jurisprudência positiva, descreve-se como o Estado interfere em todos os âmbitos, como um Deus ex machina que decide uma controvérsia que a ação livre do conhecimento jurídico positivo não solucionaria de forma evidente. O Estado também se apresenta "sempre com sua identidade inexplicável, como legislador, como executivo, como polícia, como instância de clemência, como assistência" (SCHMITT, 1996c, p.44). Isso revela que o Estado é pensado "sob muitos disfarces, mas sempre age como a mesma pessoa não visível" (SCHMITT, 1996c, p.44). A onipotência do legislador moderno não é apenas uma forma de expressão que se originou na teologia. Sempre na minúcia da argumentação surgem reminiscências teológicas. Schmitt, portanto, mostra como há de fato uma forte similitude entre teologia e teoria do Estado. Mas como ele deixa bem claro, o que ele tenta mostrar através de sua sociologia de conceitos é a estrutura comum a ambas. Além disso, é necessário perceber aqui como a visão teísta vai sendo desenhada e especificada em contraposição ao deísmo. Teísmo aqui é decisionismo.

Schmitt passa ao comentário de vários autores, relevantes no debate da época, que explicitariam a relação entre teologia e direito: Laband, Jellinek, Preu $\beta$, Stein, Bernatzik, Schulze, Gierke, Stahl, Stobbe, entre outros. Todos eles apresentam elementos importantes que ajudariam a explicitar a tese que Schmitt quer provar. Entretanto, o mais destacado de todos eles e o que é analisado com mais cuidado é Hans Kelsen. O próprio Kelsen já teria indicado desde 1920 "o parentesco metódico entre teologia e jurisprudência" (SCHMITT, 1996c, p.46). Aqui não apenas são feitos alguns comentários sobre Kelsen, mas Schmitt inicia também uma crítica às suas posições. Então, sua visão se basearia no pensamento das ciências naturais, no repúdio de todo arbítrio e na busca da expulsão de toda exceção do âmbito do espírito humano. Quando Kelsen apresenta sua visão de democracia, fica clara a forma de ciências naturais matematizadas de seu pensamento. A democracia, para Kelsen, seria "a expressão de um relativismo político e uma cientificidade livre de dogmas e de milagre, fundada no entendimento humano e na dúvida da crítica" (SCHMITT, 1996c, p.47). Aqui se percebe como a análise de Schmitt se encaminha para um duro julgamento do pensamento kelseniano. Que essa atitude em relação a Kelsen apareça em muitos momentos da obra de Schmitt é algo bem sabido. Entretanto, o que estamos querendo ressaltar é o contraste que Schmitt vai criando em relação ao teísmo e tudo o que o acompanha. Desse modo, seus adversários funcionam como uma espécie de justificação pelo avesso de suas posições.

Schmitt cita Rousseau: "imiter les décrets immuables de la Divinité". Segundo Schmitt, tal expressão, retirada do artigo Économie Politique, era típica do racionalismo do século XVIII e indicava o ideal da vida jurídica estatal. Rousseau revelaria muito bem a politização de conceitos teológicos especificamente quanto à noção de soberania. A teoria do século XVII faria a 
identificação do monarca com Deus. Tal monarca teria no Estado a mesma posição que o Deus do sistema cartesiano ocupava no mundo. Postula-se a ideia do soberano como uma unidade pessoal e o último autor. Para Schmitt, os séculos XVII e XVII eram dominados por essa visão e especialmente Hobbes permanece personalista e postula uma última instância concreta e que decide. Além disso, eleva o seu Leviatã a uma pessoa monstruosa, no sentido mitológico.

Entretanto, começa a ocorrer uma mudança sutil e contínua. É na descrição dessa mudança que podemos perceber ainda mais claramente a posição de Schmitt em relação ao decisionismo e a razão de sua crítica ao que ele denomina ora como racionalismo, ora como normativismo e, agora, como deísmo. Esse capítulo terceiro da Teologia Política, inclusive, deveria ser lido em conjunto com o breve texto A era das neutralizações e das despolitizações (1996e). Embora curto, esse texto é bastante denso e esclarecedor das posições de Schmitt. O que Schmitt passa a descrever agora com uma mudança mais pronunciada a favor do deísmo, a partir de uma contínua supremacia da visão das ciências naturais, também é indicado no texto sobre as neutralizações e despolitizações. Schmitt afirma que, de todas as mudanças da história europeia, a mais relevante foi aquela que ocorreu no século XVII, "da tradicional teologia cristã para o sistema de uma cientificidade "natural"” (SCHMITT, 1996e, p.88). Essa foi uma alteração tão marcante que "até os dias de hoje, foi determinada a direção que todo desenvolvimento posterior teria que tomar" (SCHMITT, 1996e, p.88). No cerne de tal movimento, estava a tendência para alcançar uma esfera neutra. Esse é o motivo de tal escrito: a análise de tal tendência e como ela permanece a mesma, embora sob formas diversas na história europeia. Não analisaremos essa descrição específica ${ }^{9}$. Queremos somente apontar a permanência dessa questão nos escritos de Schmitt e sua preocupação com um processo que tem a seguinte consequência: "a validade geral de uma sentença jurídica é identificada à legalidade válida da natureza, sem exceção" (SCHMITT, 1996c, p.52). É essa visão que é contraposta ao decisionismo. É como crítico a esse movimento mais amplo que Schmitt se coloca com as figuras da exceção e da decisão.

Schmitt afirma que depois do soberano ser colocado como um mero montador da máquina pelo pensamento deísta, com o êxito das ciências naturais, o mesmo soberano desaparece e a máquina funciona por si mesma. Há então uma equivalência entre a noção de vontade geral e aquela do próprio Deus e do soberano. Em um passo importante, o povo torna-se soberano. Com isso, "é perdido o elemento decisionista e personalista do conceito de soberania existente até então"

\footnotetext{
${ }^{9}$ Gostaríamos apenas de ressaltar mais uma vez os paralelos entre esses dois escritos. Logo depois da passagem que citamos de A era das neutralizações e das despolitizações, Schmitt relata como o pensamento teológico é relegado e Deus, na metafísica do deísmo do século XVII, é posto para fora do mundo. Deus se torna uma instância neutra contra todas as lutas e oposições. Já na Teologia Política, é dito que o soberano, embora fora do mundo na construção deísta, permanecia como o montador da máquina. Com esse grande movimento das ciências naturais, o soberano é finalmente desalojado e "a máquina funciona por si mesma" (SCHMITT, 1996c, p.52). Sobre a relação entre os dois escritos, ver GALLI (1996, p.333).
} 
(SCHMITT, 1996c, p.53). A vontade do povo passa a ser compreendida como boa e virtuosa. Entretanto, a unidade que se refere ao povo não pode ser comparada à unidade do soberano pessoal que emite comandos, que tem um caráter decisionista. Esse crescente enfraquecimento do caráter personalista e decisionista faz com que "o conceito de Deus teísta assim como aquele deísta tornemse incompreensíveis para a metafísica política" (SCHMITT, 1996c, p.53). Novamente, Kelsen seria o representante típico de tal movimento que marcou a metafísica e a teologia política do século XIX, ao compreender a democracia como a expressão da cientificidade impessoal e relativista. Mais uma vez, Schmitt apresenta o contraste: enquanto nos séculos XVII e XVIII o conceito de Deus pressupõe a sua transcendência perante o mundo, assim como uma transcendência do soberano em relação ao Estado, não é isso o que ocorre no século XIX. Neste, cada vez mais predominam as ideias de imanência e "todas as identidades que regressam na doutrina política e jurídica estatal do século XIX baseiam-se em tais noções de imanência" (SCHMITT, 1996c, p.53). Assim temos a tese democrática da identidade entre governantes e governados ${ }^{10}$, a doutrina do Estado orgânico e sua identidade entre Estado e soberania, a teoria jurídico estatal de Krabbe e sua identidade entre ordenamento jurídico e soberania e, por fim, a teoria de Kelsen e a identidade do Estado com o ordenamento jurídico.

Quando os escritores da restauração como Donoso Cortes, de Maistre e de Bonald desenvolveram uma teologia política, os críticos da ordem vigente se voltaram com uma crescente consciência contra a crença em Deus. Isso de forma mais nítida do que contra a expressão fundamental mais extrema da crença em uma dominação e em uma unidade. Sob a influência de Auguste Comte, Proudhon acolhe e desenvolve a luta contra Deus. Bakunin leva tal combate às últimas consequências. Schmitt relembra que entre os instruídos "todas as ideias de transcendência perecem e se torna evidente uma espécie mais ou menos clara de imanência panteísta ou então uma indiferença positivista em relação a toda metafísica" (SCHMITT, 1996c, p.54). Schmitt afirma que filosofia da imanência, cuja mais alta expressão seria Hegel (SCHMITT, 1984, p.16), introduz Deus no mundo e faz com que o direito e o Estado surjam da imanência. Nos radicais mais extremados, passa a imperar um ateísmo consequente. Os hegelianos de esquerda estavam conscientes dessas transformações e chegam à conclusão de que a humanidade teria que tomar o lugar de Deus. Esse relato de Schmitt mostra o seu julgamento desse crescente processo de uma percepção imanente do mundo. E isso acaba por revelar também sua posição em relação à democracia pensada como

10 Como bem expresso no escrito A situação histórica dos fundamentos do governo parlamentar atual: "logicamente, todos argumentos democráticos baseiam-se em uma série de identidades. A essa série pertencem: identidade de governantes e governados, regentes e súditos, identidade entre sujeito e objeto da autoridade estatal, identidade do povo com sua representação no parlamento, identidade entre Estado e povo eleitor, identidade entre Estado e lei, finalmente, identidade do quantitativo (maioria numérica ou unanimidade) com o qualitativo (correção da lei)" (SCHMITT, 1996a, p.35). 
imanência. As consequências de tal processo produzem dois fatos marcantes: "a eliminação de todas as ideias teístas e transcendentes e a formação de um novo conceito de legitimidade. O conceito tradicional de legitimidade perde patentemente toda evidência" (SCHMITT, 1996c, p.54). Deve-se notar o nexo aqui estabelecido. Se as ideias teístas e transcendentes indicavam uma certa noção de legitimidade, a crise daquelas implica o abalo desta. Schmitt não nega isso e nem propõe uma volta à noção tradicional de legitimidade.

Segundo Schmitt, desde 1848, a teoria do Estado tornou-se positiva e passa mesmo a fundar todo poder no pouvoir constituant do povo. Isso significa que no lugar do pensamento da legitimidade monárquica surge agora aquele da legitimidade democrática. Donoso Cortes, filósofo católico do Estado, representante de um pensamento decisionista e consciente do "centro metafísico de toda política" (SCHMITT, 1996c, p.55), percebeu a grande ruptura que tal movimento significava e, por causa disso, afirmou que a época da realeza chegara ao fim. Portanto, não havia mais legitimidade em sentido tradicional. A consequência de tudo isso é inevitável: a ditadura. Para Schmitt, Hobbes também chegou a tal resultado, amalgamando relativismo matemático e decisionismo consequente. Por isso, a frase tantas vezes repetida por Schmitt: auctoritas, non veritas facit legem. O final do texto é bem característico da argumentação de Schmitt e retoma a dicotomia que ele constrói. Donoso apresenta um tipo de pensamento teológico em linha com o pensamento medieval cuja estrutura é jurídica (QUARITSCH, 1988). Tudo isso é contrário à cientificidade das ciências naturais. O que tal cientificidade impede é, portanto, o decisionismo e seu caráter essencialmente jurídico e pessoal.

\section{FUNDAMENTO DA DECISÃO}

Depois de refazer brevemente a descrição mais direta do decisionismo realizada no livro Teologia Política, vamos tratar de uma questão central para o nosso tema. O ponto central de nossa discussão baseia-se na pergunta sobre o fundamento da autoridade do sujeito que decide. Dito de outra forma: por que o sujeito da decisão tem a prerrogativa de decidir, de traçar a distinção, de estabelecer uma assimetria? Quando Schmitt se refere a dois tipos de cientificidade jurídica no final do segundo capítulo da Teologia Política, ele diz que o representante clássico do tipo decisionista é Hobbes. Schmitt cita então uma passagem do Leviatã que será repetida em vários outros momentos de sua obra: auctoritas non veritas facit legem. Aqui a anteposição se dá entre auctoritas e veritas. Deve-se notar que esse é o ponto crucial do decisionismo: não só que haja uma auctoritas e não uma veritas, mas também em que se baseia tal auctoritas. Em outras palavras, qual é o fundamento da assimetria? Em uma estrutura aberta à transcendência, tal problema já está resolvido, 
inclusive quanto à centralidade do personalismo ${ }^{11}$. O personalismo no decisionismo é a indicação de que o arbítrio da decisão é deslocado para o caráter extraordinário do sujeito que decide. Aqui se revela a origem teísta desta estrutura. É interessante a argumentação de Schmitt para relacionar em Hobbes o decisionismo e o personalismo, no final do capítulo segundo da Teologia Política. É uma explicação que não explica, mas apenas descreve. O personalismo seria central em Hobbes porque ele não concebe uma ordem abstrata, uma diferença de poder abstrata. O que há é uma soberania estatal concreta ou uma diferença de poder real. Mas a resposta a nossa pergunta ainda não foi dada: em que se baseia a autoridade daquele sujeito que decide?

A questão da autoridade na Teologia Política geralmente é compreendida pelos intérpretes como se baseando no problema da ordem, como já indicamos. Aquele que decide derivaria sua autoridade da capacidade de instaurar a ordem. É interessante notar como um tema fundamental de Schmitt, o tema da realização do direito (Rechtsverwirklichung), analisado em várias obras anteriores $^{12}$, agora é traduzido em uma forma decisionista precisa. O primeiro capítulo da Teologia Política trata dessa questão que aparece como o problema da exceção ou do lugar da exceção em relação à norma. Como, para Schmitt, a exceção existe, a figura do soberano é fundamental. O soberano decide sobre a exceção e mantém o Estado, em detrimento do direito. Do ponto de vista do sentido jurídico, a ordem continua a existir, embora não como ordem legal. Aqui então fica bastante evidente o velho problema schmittiano da realização do direito (Rechtsverwirklichung). Por isso, a afirmação de que "a norma precisa de um meio homogêneo" (SCHMITT, 1996c, p.19). Por isso, também, a afirmação ainda mais exigente de que "a normalidade fática" pertence à validade imanente da própria norma. Como "não existe norma que seja aplicável ao caos", então "a ordem tem que ser estabelecida para que a ordem jurídica tenha um sentido" (SCHMITT, 1996c, p.19). O papel do soberano fica explicitado, então:

"tem que ser criada uma situação normal e soberano é aquele que decide definitivamente sobre isso, se tal Estado normal realmente impera. Todo direito é 'direito situacional'. O soberano cria e garante a situação como um todo em sua totalidade. Ele tem o monopólio dessa última decisão. Nisso repousa a essência da soberania estatal que deve ser definida, de modo correto, não como monopólio coercitivo ou de dominação, mas, juridicamente, como monopólio da decisão" (SCHMITT, 1996c, p.19).

11 Quanto à centralidade do personalismo, há uma semelhança entre a dominação carismática (WEBER, 1992, p.159-166) e a estrutura decisionista de Schmitt. Galli tem uma posição contrária a essa que estabelecemos quando trata da questão específica do soberano decisionista. Ele ressalta a diferença entre "o agir político soberano" e "o arbítrio pessoal de um indivíduo empírico" que ele acaba por aproximar ao "carisma weberiano", embora não explicite o porquê (GALLI, 1996, p.340). Mas se a dominação carismática fosse apenas "o arbítrio pessoal de um indivíduo empírico", ela nem mesmo seria exatamente dominação [Herrschaft] para Weber. Uma posição muito mais matizada do próprio Galli encontra-se na nota 46, da página 119 de seu livro. Nesta nota muito instrutiva são citadas as várias referências do própriob Schmitt ao tema weberiano da dominação carismática, assim como alguns estudos que analisam a questão.

${ }^{12}$ Ver, por exemplo, o prefácio à primeira edição de 1921 de A Ditadura. A noção de ditadura está diretamente relacionada ao problema da realização do direito (SCHMITT, 1994, XIII-XX). 
Há uma relação direta entre exceção e autoridade estatal, pois "o estado de exceção revela a essência da autoridade estatal da forma mais clara. Aqui a decisão se separa da norma jurídica e, para formular paradoxalmente, a autoridade comprova que ela, para criar direito, não precisa ter direito" (SCHMITT, 1996c, p.19). O que Schmitt revela é a relação que existe entre a autoridade e a necessidade de se criar a "situação normal" e efetivar o direito. Como dissemos, o velho problema da realização do direito (Rechtsverwirklichung) retorna agora, de modo acentuado, na forma da discussão sobre a soberania e a exceção.

A estrutura decisionista permanece na Teoria da Constituição. A Constituição para Schmitt é decisão e ele chega mesmo a falar em decisão existencial. Além disso, tal decisão pressupõe, como não poderia deixar de ser, um sujeito. Tal sujeito, o sujeito do poder constituinte, é relacionado claramente à noção de vontade. E se a base da autoridade na forma do decisionismo da Teologia Política é a capacidade para estabelecer a ordem, algo semelhante ocorre na Teoria da Constituição. Schmitt afirma: “toda unidade política existente tem seu valor e sua 'razão de existência' não na justiça ou utilidade de normas, mas em sua existência” (SCHMITT, 2003, p.22). Há uma questão de fundo sobre a unidade se justificar apenas por ter a capacidade de exisitir enquanto unidade. Há uma circularidade aqui, quase uma tautologia nesse argumento "existencial".

Embora sempre seja necessário ter cautela na aproximação entre Teologia Política (1996c) e Sobre os três modos do pensamento jurídico (2006), neste último escrito, ao qual já nos referimos, Schmitt estabelece ainda mais explicitamente uma relação entre autoridade e capacidade de realizar o direito. Mais uma vez Hobbes é denominado o caso clássico do decisionismo. O direito é decisão do soberano e soberano não é uma derivação de alguma legitimidade, mas aquele que decide soberanamente. Direito é lei e lei é comando que decide o conflito. O enunciado é repetido: auctoritas non veritas facit legem. Nesse momento, para Schmitt, mesmo a distinção entre auctoritas e potestas ${ }^{13}$ desaparece, pois a decisão soberana é summa auctoritas e summa potestas. É afirmado, então, que "quem estabelece a tranquilidade, a segurança e a ordem, é soberano e tem toda a autoridade" (SCHMITT, 2006, p.23). Essa é a frase na qual, de forma mais inequívoca, Schmitt associa a autoridade do soberano à sua capacidade de produzir ordem.

Como dissemos, é interessante perceber que várias abordagens tendem a minimizar a importância da estrutura do decisionismo, originalmente teísta, em Schmitt. No fundo, o decisionismo e sua estrutura teísta é algo tão exigente e tão radical que parece haver constantemente uma tentativa por parte de vários intérpretes de domesticar, de conter, de sujeitar a radicalidade do decisionismo schmittiano. O problema dessa estratégia é minimizar a importância das noções de

${ }^{13} \mathrm{O}$ par conceitual auctoritas e potestas é aproximado do par, em oposição, régner e gouverner, do debate constitucional francês do século XIX (SCHMITT, 1996b, p.135-136). 
exceção, decisão e do lugar do sujeito da decisão. Faremos uma descrição da estrutura mais geral do decisionismo para ressaltar os elementos que são relevantes para nossa discussão sobre a democracia.

A estrutura mais abstrata do decisionismo é uma figura de dois lados: regra e exceção. A questão da regra só é entendida se contrastada com a exceção. A exceção é, exatamente, a ausência da regra. O que esta figura procura destacar é claramente a questão do princípio, do início da regra. Ao mesmo tempo, ela tem como função negar qualquer tipo de solução para o fundamento da regra com a possibilidade da existência de uma regra anterior. Isso seria deísmo. Esse é o grande adversário de Schmitt. Se houvesse uma regra anterior, qualquer que seja o seu estatuto, o problema do fundamento, o problema do início não existiria. O problema do começo perderia qualquer especificidade ou premência. Se já há uma regra (uma distinção), então o fundamento é essa regra. Aqui o deísmo pode tomar várias formas, mas a estrutura permanece. O importante é que a regra já esteja de certo modo justificada por outra regra previamente existente. Obviamente que tal regra anterior guardará algum tipo de ascendência sobre as outras regras da sequência. Se for esse o caso, então, nesse sentido preciso, não há decisão. Todo o peso do ato de decidir e a grave responsabilidade que decorre dessa distinção sem parâmetro prévio, portanto, necessariamente arbitrária do ponto de vista normativo, tudo isso é diluído, na verdade, em uma quase dedução da regra anterior. Portanto, não há vontade. O que predomina é ratio e não voluntas. Nesse sentido preciso, não há nenhum arbítrio, pois não há decisão em sentido eminente, apenas dedução de algo que já existe. Dito de outro modo, a distinção, a partição que decorre de uma decisão, o ato que inaugura radicalmente algo novo, esse verdadeiro começo, tudo isso é eliminado pelo deísmo.

O que nos interessa aqui é ressaltar que há dois campos definidos: a exceção e a regra. A pergunta clássica, então, é como se dá a passagem de um para o outro, como se passa da exceção para a regra. Novamente, essa é uma pergunta que só surge quando não se está situado na estrutura deísta. A crítica reiterada de Schmitt é que, no esquema deísta, essa pergunta nunca surge, o que apenas ocultaria o momento imprescindível da decisão. A passagem de um momento a outro, de um espaço a outro é feita por uma decisão, por um corte, por uma distinção. Há uma cisão que inaugura uma diferença e uma assimetria: eis o surgimento da regra. Isso é decisão. Mas para Schmitt, para o teísmo, para toda estrutura antropomórfica que seja uma continuação do teísmo, toda decisão pressupõe um sujeito. Então, deve-se perceber como todo o peso do começo e toda a responsabilidade do início são deslocados para o sujeito. Por isso, esse sujeito obviamente não é um sujeito qualquer, ele é o sujeito que ocupa um papel fundamental. Ele é o sujeito que decide, que separa, que faz a cisão, que traça a distinção, que funda a regra e instaura a ordem. Todo o peso, a incerteza e o arbítrio da decisão, do ponto de vista normativo, são transportados para essa figura eminente e para sua capacidade de estabelecer a ordem. Não é fortuito que Schmitt sempre volte ao 
problema do lugar desse sujeito, do status dessa figura, da origem de sua situação de assimetria. Esse é a questão que sempre volta na forma da pergunta sobre auctoritas. No fundo, auctoritas tenta apontar a justificativa de uma assimetria e o claro problema decorrente é em que ela se funda. Por isso, no decisionismo, se a decisão é necessariamente arbitrária, do ponto de vista normativo, porque não há norma que justifique a decisão, então, é a ordem estabelecida pelo sujeito que decide aquilo que limita tal arbitrariedade e funda tal decisão. Se o momento da passagem da exceção à regra é feito pelo sujeito que decide, se a decisão é realmente um ato que inaugura, então, necessariamente, "a decisão, considerada normativamente, nasce do nada" (SCHMITT, 1996c, p.37). Toda vez que se quer enfraquecer o decisionismo, é exatamente esse o ponto a ser criticado. Mas a decisão ou nasce do nada ou não é uma decisão e tem-se apenas deísmo, imanência. Por outro lado, a auctoritas desse sujeito que decide acaba por "solucionar" o problema da arbitrariedade da decisão, na medida em que ele estabelece a ordem. A assimetria é deslocada da decisão para o sujeito da decisão que instaura a ordem. A auctoritas funda essa assimetria. Outro ponto fundamental é que, nessa estrutura decisionista, há um dualismo constitutivo que pode ser unido apenas pelo sujeito que decide. Ocorre, então, que, do ponto de vista do espaço da regra, o sujeito ocupa uma ambígua posição de exterioridade ${ }^{14}$. Não se trata de imanência, trata-se de teísmo, de decisionismo.

\section{DEMOCRACIA COMO IMANÊNCIA}

Vamos agora ao cerne da questão aqui proposta: a relação entre soberania, decisionismo e democracia como imanência. Qual é o problema da democracia como imanência para Schmitt? Qual é o problema de uma estrutura decisionista para se pensar a democracia como imanência? Quais seriam, então, os traços principais da democracia como imanência? Essas são as perguntas que pretendemos responder.

É da imanência que se deve partir para se se pensar a democracia. A democracia ocorre na imanência e surge devido à imanência. Não há exterioridade do sujeito que decide em relação à regra da democracia. A circularidade implica necessariamente um mesmo campo onde se situam sujeitos e regras, cidadãos e leis. A exterioridade é impossível na imanência. Por isso, também, no sentido schmittiano do termo, não há soberano. Não há soberano teísta porque não há exceção, não há milagre na democracia, só há a regra e nada fora dela. Não há dualismo na democracia. Todo o problema que, no fundo, preocupa Schmitt, a saber, o conflito, não é resolvido pelo recurso a um

\footnotetext{
${ }^{14}$ Essa ambiguidade fica muito clara em Schmitt: o soberano "situa-se fora da ordem legal normalmente válida e, no entanto, pertence a ela, pois ele é competente para a decisão de suspender a Constituição in toto" (SCHMITT, 1996c, p.14).
} 
agente externo aos participantes. Aquele que decide é uma instância autorizada pela regra, que decide sobre a regra, dentro da regra.

Entretanto, quando se afirma que aquele que decide pertence à regra, sempre permanece a questão: e aquele que decide em última instância? Se é inevitável que exista a figura daquele que decide de modo último, pois o conflito nunca pode ser eliminado, então, algo do lugar do soberano deve ser retomado. Sendo assim, algo do soberano parece não poder ser extinto do campo político e jurídico. Há que se decidir, pois o campo das regras não é algo mecânico nem autoevidente.

Contudo, se a figura do soberano se faz necessária, então ela deve ser reabilitada fora do teísmo, fora do decisionismo teísta, pois o tempo da democracia é o tempo da imanência. Em outras palavras, a democracia deve retomar com toda seriedade o lugar e o papel do soberano, mas, paradoxalmente, dentro da própria regra. Sendo assim, o que torna atual a pergunta sobre o sujeito da soberania não é o caso de exceção, como Schmitt afirma, pois esse simplesmente não existe na democracia. A exceção é uma figura estranha à democracia, pois impossível na imanência. A exceção na democracia é simplesmente o prenúncio da guerra civil e o fim da própria democracia. Além disso, a noção de exceção está muito presa a uma dicotomia composta por máquina e vida, necessidade e contingência, ou seja, regra e exceção. A compreensão da democracia enquanto fenômeno político e jurídico deve ultrapassar essa dicotomia. É nesse sentido que a figura do soberano deve ser retomada. E tal figura é necessária, pois há um fato percebido por toda uma tradição jurídica que refletiu sobre essa questão: uma regra não se aplica por si mesma. Além disso, deve-se reconhecer que o conflito é constitutivo, o conflito nunca é eliminado. Portanto, é necessário determinar o lugar daquele que decide em última instância. Mas se não há nenhuma figura que se situe fora da regra, quem é aquele que decide em última instância, então?

Propomos, então, uma definição a partir da estrutura da imanência. Soberano não é aquele que decide sobre a exceção, esse caminho está fechado para a democracia. Quem é o soberano, então? O soberano da democracia é o soberano imanente, a saber, aquele que decide sobre a regra dentro da regra. Uma espécie de circularidade é inevitável ${ }^{15}$. Nenhuma assimetria fundante e salvadora pode resolver essa circularidade. E isso diz respeito inclusive à Constituição. A Constituição não pode ser tal assimetria porque ela necessita de interpretação. Não existe Constituição além do embate permanente de interpretações. Não existe Constituição antes das

\footnotetext{
15 Toda definição de um soberano imanente apresenta algum tipo de circularidade, não há como evitar isso. Por exemplo, soberano é aquele que determina a interpretação correta da regra da democracia dentro da regra da democracia. Ou, ainda, soberano é aquele que interpreta a correta adequação da legalidade à regra da democracia, contudo, dentro da legalidade. Ou, também, o lugar do soberano é aquele em que a diferença entre regra e lei desaparece, pois não há mais um espaço para além da legalidade como interpretação. Por fim, o soberano imanente é aquele que tem uma competência legal para decidir sobre competências, inclusive a sua própria. Como dissemos, a circularidade é inevitável.
} 
interpretações ${ }^{16}$. A Constituição é a interpretação da Constituição. A questão, então, é quem interpreta em última instância. Como a Constituição não existe "em si", o soberano imanente é aquele que realiza a interpretação final, entre as várias interpretações possíveis. Novamente, a circularidade. O soberano imanente, portanto, não decide, mas interpreta. Sua interpretação é aquela que vale como a palavra final no conflito interpretativo. Em relação à questão do soberano, fica claro como sua decisão (derivada de uma interpretação), na democracia como regra, ocorre no âmbito da imanência. Não há decisionismo teísta aqui, há uma decisão (derivada de uma interpretação) de um soberano imanente dentro da regra.

O que é primeiro na democracia não é uma decisão, mas uma regra, a regra da democracia, ou seja, a regra da autodeterminação. Entretanto, nenhuma regra é autoevidente e tem sentido a partir de si mesma. Toda regra é regra interpretada e há sempre várias interpretações possíveis, por isso o conflito ${ }^{17}$. Além disso, toda interpretação é um ato de criação que se coloca em uma dupla tensão: por um lado, oferece uma novidade ou diferença em relação ao sentido já posto, por outro lado, tem necessidade de estabelecer alguma relação com esse sentido posto. É dessa tensão constitutiva que surge uma interpretação possível. Exatamente por isso, podemos descrever esse ato interpretativo como uma decisão imanente, a saber, uma espécie paradoxal de "inovação redundante".

Colocado de modo direto: qual é o problema da abordagem schmittiana da democracia? Dito claramente: o problema da abordagem schmittiana da democracia, aquilo que não apenas dificulta, mas, no fundo, impede qualquer compreensão do que vem a ser a democracia por Schmitt, é o seu decisionismo teísta como estrutura de fundo ${ }^{18}$. Ou, o que significa a mesma coisa, a sua recusa consciente da imanência e de tudo o que ela implica. $\mathrm{O}$ decisionismo guarda a estrutura vertical, mesmo já tendo perdido a abertura para a transcendência. Por isso, as inúmeras críticas à

\footnotetext{
${ }^{16}$ Mesmo Kelsen, tão criticado por Schmitt como deísta e racionalista, sabia muito bem disso. Isso aparece com clareza no polêmico capítulo sobre a interpretação da Teoria Pura do Direito (KELSEN, 1994, p.90-106).

${ }^{17}$ Se houvesse consenso sobre a regra, não haveria necessidade do soberano. Dito de outra forma, o soberano somente é necessário porque há conflito. Por isso, o soberano é aquele que, entre outros que interpretam de forma distinta e mesmo oposta, tem a decisão final. A questão do conflito é intensificada na imanência porque não há uma figura superior situada fora da regra, pois todos se constituem pela regra. Este é o sentido forte de imanência. Qual seria, então, o critério que define quem é o soberano entre diferentes interpretações? O critério é aquela interpretação que é tomada como final, pois aceita pela maioria daqueles que estão dentro da regra democrática.

${ }^{18}$ Talvez seja temerária a afirmação de que o decisionismo estrutura toda a obra de Schmitt. De todo modo, já no primeiro parágrafo da introdução da Teologia Política II, publicada em 1970, estão presentes todos os temas caros ao decisionismo (SCHMITT, 1996d, p.12). A crítica à ideia de superação de toda teologia política ou metafísica política pela ciência. A referência ao teísmo e sua relação com o decisionismo. Não sem ironia, o reconhecimento da "morte" de Deus. A crítica à visão da imanência, que acaba por prevalecer, e à circularidade que dela deriva, circularidade expressa nas noções compostas com o prefixo "auto" (selbst). É tão marcante a permanência das questões em Schmitt, que poderíamos até mesmo iniciar nossa crítica à sua visão de democracia exatamente por essa introdução. $\mathrm{O}$ que estamos afirmando é que democracia deriva necessariamente da imanência e da circularidade, portanto, o sufixo "auto" sempre se encontra presente. Por isso, democracia é necessariamente autodeterminação, autolegislação, autorreferência.
} 
imanência, por isso a recorrente redução da imanência ao individualismo, ao econômico, ao técnico. O corolário da recusa da imanência é a concomitante rejeição da democracia. Quem adentra o maravilhoso e fascinante espaço da exceção, na imanência, irá se deparar apenas com o mais puro arbítrio. A transcendência encontrou o seu fim. Resta apenas a nostalgia.

Um ponto deve ser destacado com clareza. O problema da abordagem da democracia realizada por Schmitt que estamos ressaltando não se relaciona diretamente à sua atitude contra o liberalismo. Que Schmitt se bata em toda a sua obra contra o liberalismo é algo óbvio ${ }^{19}$. O que queremos mostrar é que há uma questão específica em relação à democracia em Schmitt que independe de seu antiliberalismo. O problema de uma compreensão da democracia em Schmitt reside fundamentalmente na estrutura do decisionismo teísta, o que se situa além de seu antiliberalismo.

\section{CONSIDERAÇÕES FINAIS}

Nosso artigo partiu do decisionismo de Schmitt, noção essa que se constitui central em seus escritos. De fato, o decisionismo revela a estrutura mais abrangente do pensamento político e jurídico de Schmitt. Destacamos alguns elementos da noção de decisionismo, buscando apresentar sua estrutura vertical teísta. Nesta análise, surgiram as figuras do soberano teísta e da exceção. O soberano schmittiano e o espaço da exceção estão estreitamente ligados. Na verdade, são os dois lados de uma mesma forma. A partir disso, analisamos o problema do fundamento da decisão, indicando o tema da ordem dentro da questão mais ampla, e sempre presente em Schmitt, da realização do direito (Rechtsverwirklichung). Finalmente, apresentamos a questão da democracia e da imanência. A democracia é uma figura da imanência, pois seu pressuposto e sua apresentação. Sendo assim, toda a figuração vertical do decisionismo schmittiano tem que ser abandonada para o correto entendimento da imanência e, portanto, da democracia. A democracia, tomada como imanência, impede as figuras do soberano teísta e da exceção. Como dissemos, a transcendência não tem mais lugar, restando apenas a nostalgia. A regra da democracia é a autodeterminação, regra essa que só pode ser realizada por aqueles que se situam dentro dela. Por outro lado, como regras não se autoinstituem e devido ao fato fundamental do conflito, é necessário que alguém tenha a palavra final, entretanto, dentro da regra. É por isso que surge o soberano imanente, determinado por sua atuação como intérprete último da regra, dentro da regra. Não há mais um espaço situado "fora" que, exatamente por essa localização, resolveria as disputas por sua posição superior. O

${ }^{19}$ Essa relação com o liberalismo é bem explorada por Strauss em seu breve escrito Notas sobre O Conceito do Político de Carl Schmitt: "Schmitt realiza a crítica ao liberalismo em um mundo liberal e sugerimos, deste modo, que sua crítica ao liberalismo ocorre no horizonte do liberalismo" (STRAUSS, 1995a, p.119). 
intérprete último da regra se situa dentro da regra, sendo, por isso, o soberano imanente da democracia.

Apresentaremos, por fim, apenas mais dois pontos do que seria a imanência da democracia ou a democracia imanente: a centralidade do conflito, por isso a necessidade do soberano imanente. O primeiro seria a rejeição de qualquer estrutura vertical como transcendência para pensar a democracia. A democracia, por ser resultado e consequência da imanência, tem que ser pensada a partir de estruturas horizontais. Por outro lado, há hierarquia na democracia. A alternativa a hierarquias seria um otimismo extremo quanto à capacidade de solução de conflitos, como se eles se resolvessem por si mesmos. Isso não é uma contradição, mas exatamente o desafio teórico da democracia: como pensar hierarquias a partir de estruturas imanentes? Como pensar assimetria a partir do simétrico? O conflito é o pano de fundo do problema.

Se o conflito é posto como ponto de partida da forma democrática, então há a necessidade de ser retomada a figura do soberano. Desconsiderar a figura do soberano significa ter uma visão otimista sobre os conflitos e sua solução. Mas aqui não se trata mais do soberano teísta de Schmitt. O soberano tem que ser trazido para a imanência. O soberano não se situa fora da regra da democracia, ou seja, fora do jogo. O soberano se situa dentro da regra, ele não decide a partir do nada, ele interpreta a partir da regra. O soberano imanente pertence à forma da democracia e a refaz a cada decisão. Ele é o responsável pela última interpretação da regra, entre as várias interpretações sugeridas. Isso é imanência, essa é a regra da democracia.

\section{REFERÊNCIAS BIBLIOGRÁFICAS}

GALLI, Carlo. Genealogia della politica. Carl Schmitt e la crisi del pensiero político moderno. Bologna: Il Mulino, 1996.

HABERMAS, Jürgen. Legitimation Crisis. Boston: Beacon Press, 1975.

HOFMANN, Hasso. Legitimität gegen Legalität. Der Weg der politischen Philosophie Carl Schmitts. 4. Auflage mit einer neuen Einleitung. Berlin: Duncker \& Humblot, 2002.

Repräsentation. Studien zur Wort- und Begriffsgeschichte von der Antike bis ins 19. Jahrhundert. Vierte Auflage mit einer neuen Einleitung. Berlin: Duncker \& Humblot, 2003.

KELSEN, Hans. Reine Rechtslehre. Einleitung in der Rechtswissenschaftliche Problematik. 1. Auflage. Pfungstadt: Scientia Verlag Aalen, 1994.

PITKIN, Hanna. The concept of representation. Berkeley, Los Angeles: University of California Press, 1967. 
QUARITSCH, Helmut. "Die Zweideutigkeit der ,Entscheidung“ - Thomas Hobbes und Juan Donoso Cortés im Werk Carl Schmitts“. In: Complexio Oppositorum. Über Carl Schmitt. Berlin: Duncker \& Humblot, 1988, p.193-232.

SCHMITT, Carl. Die Diktatur.Von den Anfängen des modernen Souveränitatsgedankes bis zum proletarischen Klassenkampf. Sechste Auflage. Berlin: Duncker \& Humblot, 1994.

Die geitesgeschichtliche Lage des heutigen Parlamentarismus. Achte Auflage. Berlin: Duncker \& Humblot, 1996a.

Der Hüter der Verfassung. Vierte Auflage. Berlin: Duncker \& Humblot, 1996b.

Politische Theologie. Vier Kapitel zur Lehre von der Souveränität. Siebente Auflage. Berlin: Duncker \& Humblot, 1996c.

Politische Theologie II. Die Legende von der Erledigung jeder Politischen Theologie. Vierte Auflage. Berlin: Duncker \& Humblot, 1996d.

1984.

Römischer Katholizismus und politische Form. 2. Auflage. Stuttgart: Klet-Cotta, . Verfassungslehre. Neunte Auflage. Berlin: Duncker \& Humblot, 2003.

Über die drei Arten des rechtswissenschaftlichen Denkens. Dritte Auflage. Berlin: Duncker \& Humblot, 2006.

. "Das Zeitalter der Neutralisierungen und Entpolitisierungen". In: . Der Begriff des Politischen. Text von 1932 mit einem Vorwort und drei Corollarien. Berlin: Duncker \& Humblot, 1996e, p.79-95.

STRAUSS, Leo. "Notes on Schmitt's The Concept of the Political". In: MEIER, H. Carl Schmitt \& Leo Strauss. The hidden dialogue. Chicago, London: The University of Chicago Press, 1995a, p.89-120.

. "Three Letters from Strauss to Schmitt". In: MEIER, H. Carl Schmitt \& Leo Strauss. The hidden dialogue. Chicago, London: The University of Chicago Press, 1995b, p.121-131.

VOEGELIN, Eric. The New Science of Politics. An Introduction. Chicago, London: The University of Chicago Press, 1952.

WEBER, Max. "Die drei reinen Typen der legitimen Herrschaft". In: Universalgeschichtliche Analysen. Politik. Stuttgart: Kröner, 1992, p.151-166. . Soziologie. 